\title{
Tachycardia-induced unexpected pacemaker behaviour
}

\author{
A. Bôhm • R. G. Kiss • G. Z. Duray
}

Published online: 16 October 2014

(C) The Author(s) 2014. This article is published with open access at Springerlink.com

A Adapta ADDR01 pacemaker was implanted in a 67year-old female patient due to intermittent complete atrioventricular (AV) block. Appropriate pacemaker operation was detected at regular follow-ups: atrial/ ventricular threshold $0.5 / 1 \mathrm{~V}, \mathrm{P} / \mathrm{R}$ amplitude $2.8 /$ $22 \mathrm{mV}$, lower rate $45 \mathrm{bpm}$, upper track $140 \mathrm{bpm}$. Later follow-ups detected pacemaker dependency due to the progression of AV conduction disturbance. Three years after implantation, frequent paroxysmal tachycardias occurred. Holter monitoring recorded the arrhythmia causing the symptoms (Fig. 1).

What is the mechanism of this arrhythmia and unexpected pacemaker operation?

You will find the answer elsewhere in this issue.

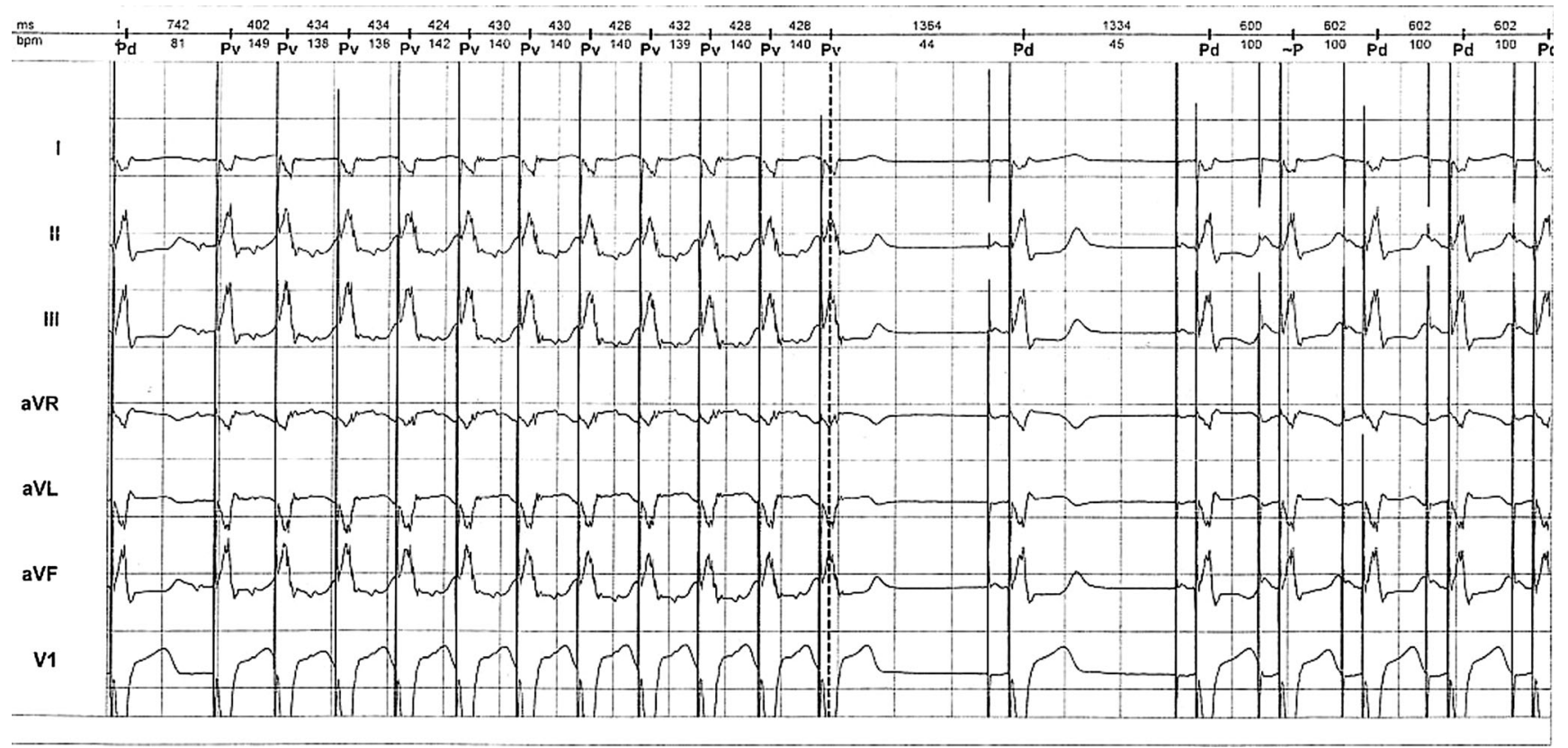

Fig. 1 Holter recording of arrhythmia

A. Böhm $(\bowtie) \cdot$ R. G. Kiss · G. Z. Duray

Department of Cardiology, Military Hospital, Róbert K körut 44,

Budapest, Hungary 1344

e-mail: abohm@freemail.hu
Conflict of interest None.

Open Access This article is distributed under the terms of the Creative Commons Attribution License which permits any use, distribution, and reproduction in any medium, provided the original author(s) and the source are credited. 